\title{
Efficacy of Korean Red Ginseng in the Treatment of Atopic Dermatitis
}

\author{
Kyung Goo Lee and Sang Wook Son* \\ Department of Dermatology, Korea University College of Medicine, Seoul 136-705, Korea
}

In order to determine the efficacy of functional foods, objective measurement of the severity of atopic dermatitis (AD) after taking foods is important. The aim of this study was to conduct an objective evaluation of whether Korean red ginseng (KRG) might be helpful for improvement of skin condition and serum IgE in patients with AD. Thirty atopic patients (18 females and 12 males) participated in this study. Patients took KRG for 16 weeks. Bioengineering methods, including the corneometer and evaporimeter, were used at the start of the study and after 8 weeks and 16 weeks. In addition, we assessed serum IgE levels and the severity scoring of the atopic dermatitis (SCORAD) index. Transepidermal water loss and skin hydration showed significant improvement after 16 weeks. A significant decrease in the SCORAD index, as well as in serum IgE level, was observed after 16 weeks. Our results demonstrated that KRG may be helpful as a functional food for patients with AD.

Keywords: Atopic dermatitis, Korean red ginseng, Bioengineering methods, Serum IgE

\section{INTRODUCTION}

As the rate of prevalence and severity of atopic dermatitis (AD) have shown a continuous increase, new therapeutic modalities are being rapidly developed. To date, immunological disorder has been regarded as a main pathogenic factor of $\mathrm{AD}$; however, epidermal barrier function disorder has recently been considered as another main factor causing $\mathrm{AD}$ [1-3]. As targeting of epidermal barrier function disorder may treat $\mathrm{AD}$, application of emollients, soaking baths, etc. are now used collaterally with conventional therapeutic modalities such as topical corticosteroid application and antihistamine medication. Because $\mathrm{AD}$ is a chronic relapsing disease [4,5], development of safer and more convenient treatment modalities with higher compliance is needed.

In Korea, Korean red ginseng (KRG) is used widely and frequently as a health supplement food. Unlike other medications, long term application of KRG is associated with low rates of side effects; therefore, it has lower reluctance and higher compliance. As a result, few patients avoid taking KRG for a long term period.

Bae et al. [6] and Shin et al. [7] reported on an antiinflammatory effect of KRG (the steamed root of Panax ginseng Meyer, Araliaceae) in a passive cutaneous anaphylaxis reaction, contact dermatitis, and psoriasis in a mouse model trial. Hence, in this article, the authors attempted to conduct an objective investigation of the clinical efficacy of KRG in AD using proven cuttingedge medical engineering and clinical index.

\section{MATERIALS AND METHODS}

\section{Patient characterization}

Following criteria for diagnosis of Korean AD patients, 30 patients diagnosed as $\mathrm{AD}$ were enrolled.

\section{Inclusion criteria}

1) AD patients who received an explanation of the objective, methods, and efficacy of this clinical trial and

\footnotetext{
(c) This is an Open Access article distributed under the terms of the Creative Commons Attribution Non-Commercial License (http://creativecommons.org/licenses/by-nc/3.0/) which permits unrestricted non-commercial use, distribution, and reproduction in any medium, provided the original work is properly cited.
}

Received 21 Oct. 2010, Revised 30 Mar. 2011, Accepted 31 Mar. 2011

*Corresponding author

E-mail: skin4u@korea.ac.kr

Tel: +82-2-920-6433, Fax: +82-2-928-7540 
Table 1. Sex ratio of atopic patients

\begin{tabular}{lc}
\hline & Patient no. (n) \\
\hline Male & 12 \\
Female & 18 \\
Total & 30 \\
\hline
\end{tabular}

Table 2. Age of atopic patients

\begin{tabular}{lc}
\hline & Average age \\
\hline Male & 16.9 \\
Female & 17.8 \\
Total & 17.3 \\
\hline
\end{tabular}

who agreed to participation. 2) Patients who had been diagnosed as AD. 3) Age over 7 years old.

\section{Exclusion criteria}

1) Patients receiving medication for another disease. 2) Patients who were pregnant or breast feeding. 3) Patients who were allergic to this component of KRG. 4) Patients who had been enrolled in another clinical study within 3 months. 5) Patients who were not able to understand the objectives and methods of this clinical trial. 6) Patients who has been treated with other products or medication within 2 weeks before initiation of this clinical study. 7) Other patients considered by the clinician to be inappropriate for participation in this clinical study.

The patient group included a total of 30 patients, 18 female patients and 12 male patients (Table 1). Patients' ages ranged from 7 to 41 years old and mean age was 17.3 years old (Table 2).

\section{Study design}

KRG was prescribed ( $3 \mathrm{~g}$ /day) to $30 \mathrm{AD}$ patients for a period of 16 weeks. Skin investigation was made at 2 $\mathrm{cm}$ distal from the ante-cubital wrinkle line before initiation of medication and after 8 weeks and 16 weeks using medical engineering tools. Severity scoring of the atopic dermatitis (SCORAD) index was also performed at the same time. In addition, blood sampling was performed using the same method in order to monitor the difference of serum IgE concentration before and after medication.

\section{Measurement of severity using medical engineer- ing methods}

Thirty minutes before investigation of skin using medical engineering tools, patients rested under conditions of room temperature constantly ranging between $22^{\circ} \mathrm{C}$ to $24^{\circ} \mathrm{C}$ and relative humidity ranging between $38 \%$ to
$42 \%$, which allowed them to adapt to the investigational environment [8].

\section{D-Squame}

$D$-Squame (Cuderm, Dallas, TX, USA) is a roundshaped tape with a $22 \mathrm{~mm}$ diameter uniformly covered with adhesive material. This tape is made to catch the outermost falling off keratinocytes, which enables quantification of degree of dryness of skin. After compression of the tape for 3 seconds, a Pulnix Tm-7CN monochrome CCD camera (Pulnix America Inc., Sunnyvale, CA, USA) and RGB monitor (PVM 1342Q; Sony Co., Tokyo, Japan) were used for measurement of the distribution and density of attached keratinocytes. This result was analyzed using an image analyzer (AIC Inc., Princeton, NJ, USA), and desquamation index (DI) and scaling index (SI) were calculated using this mathematical formula $[9,10]$.

\section{Evaporimeter}

Vertical compression of a $12 \mathrm{~mm}$ diameter probe on skin results in development of a water vapor gradient between the surface of the skin and surrounding air. The two humidity sensors in the probe of the evaporimeter (Dermalab; Cortex Technology, Hadsund, Denmark) measure the gradient difference of relative humidity, and, based on this difference, transepidermal water loss (TEWL) can be calculated. The authors measured TEWL 3 times for the same area and the mean value was obtained [11].

\section{Corneometer CM 825}

Corneometer CM 825 (Courage-Khazaka, Koln, Germany) is a device that measures degree of skin surface moisture using electrical capacitance of skin surface. Following vertical pressure with a $16 \mathrm{~mm}$ diameter probe on skin, measurement of electrical capacitance can be performed, which closely correlates with skin moisture content [12-14]. The authors performed measurements using the corneometer 3 times for the same area and the mean value was obtained.

\section{Measurement of serum IgE}

Serum IgE was measured by an immunoassay method using Enzygnost-IgE monocloncal (Behringwerke AG, Marburg, Germany). Twenty microliters of IgE standard SI was extracted into test tubes 1 and 2 and $20 \mu \mathrm{L}$ of SI (IgE standard SI) was extracted into test tubes 3 and 4. Using the same method, $20 \mu \mathrm{L}$ of IgE control serum was placed in test tubes 5 and 6 and patients' serum was pi- 


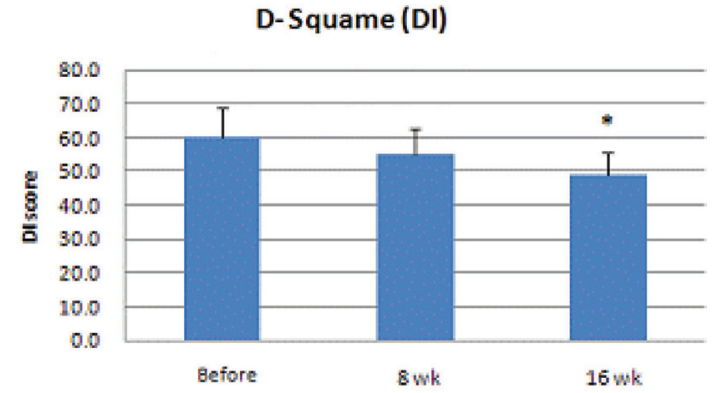

Fig. 1. Result of desquamation index (DI) measurement. DI decreased after initiation of Korean red ginseng medication. At the 8th week, no significant decrease was observed; however, at the 16th week, decrease of the DI was significant $\left({ }^{*} p<0.05\right)$.

petted into test tubes 7 and 8 .

After washing all test tubes 3 times with washing solution, $200 \mu \mathrm{L}$ of chromogen buffer/substrate solution was added and left still in $20^{\circ} \mathrm{C}$ to $25^{\circ} \mathrm{C}$ for 30 minutes. After 30 minutes, $1,000 \mu \mathrm{L}$ stopping solution was added and a photometer was used for measurement of serum $\operatorname{IgE}$ level [15].

\section{Measurement of severity by the SCORAD index}

SCORAD index is calculated by the formula presented by The European Task Force on Atopic Dermatitis [16]. Reference evaluation systems $(0-103)=$ extent $/ 5(0-20$, $19.4 \%)+3.5 \times$ intensity $(0-63,61.2 \%)+$ subjective symptoms $(0-20,19.4 \%)$. The extent was calculated by "rule of nine", ranging from 0 to 100 , and intensity was scored from 0 to 3 in 6 items: erythema, edema/papulation, oozing/crust, excoriation, lichenification, and dryness. Subjective symptoms index, including severity of pruritus and sleep disturbance within the recent 3 days, was acquired using a 10 point scale. Following acquisition of these scores, SCORAD was calculated according to the formula above.

\section{Statistical analysis}

The SPSS ver. 12.00 (SPSS Inc., Chicago, IL, USA) program was used for all statistical analyses. A $p$-value under 0.05 was considered a significant result. ANOVA or paired t test was also used.

\section{RESULTS}

\section{Result of measurement of severity using medical engineering methods \\ D-Squame}

Both desquamation index and scaling index showed a decrease after initiation of KRG medication, and, espe-

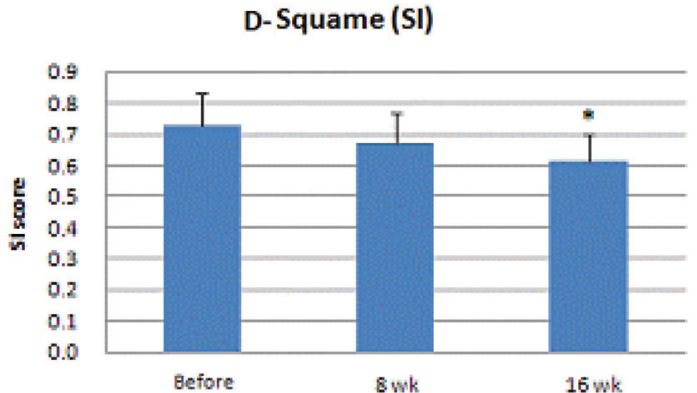

Fig. 2. Result of scaling index (SI) measurement. SI also decreased after initiation of Korean red ginseng medication. At the 8th week, no significant decrease was observed; however, at the 16th week, SI showed a significant decrease $\left({ }^{*} p<0.05\right)$.

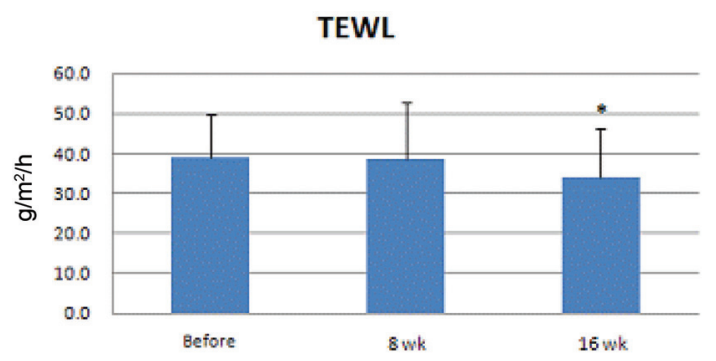

Fig. 3. Transepidermal water loss (TEWL) measurement value decreased after taking medication. At the 8th week, no significant decrease was observed; however, at the 16th week, TEWL value showed a significant decrease $\left({ }^{*} p<0.05\right)$.

cially at the 16th week after, DI and SI showed a significant decrease $(p<0.05)$ (Figs. 1 and 2).

\section{Evaporimeter}

TEWL value using the evaporimeter ranged from 21.3 to 63.3 , and the mean value was 38.8 . TEWL value started to decrease after initiation of medication, and at the 16th week, the value showed a significant decrease $(p<0.05)$ (Fig. 3).

\section{Corneometer CM 825}

Corneometer measurement value ranged within 32.6 to 74.8 and the mean value was 40.0 . Skin surface moisture rate increased and was significantly higher at the 16th week $(p<0.05)$ (Fig. 4).

\section{Measurement of serum IgE}

Serum IgE level ranged from 82 to over 5,000 and the mean value was 1049.3. This result correlated with the increased value of serum $\mathrm{IgE}$ in $\mathrm{AD}$ patients. At the 16th week, mean value was 588.9, which demonstrated a significant diminution of serum IgE level $(p<0.05)$ (Fig. 5). 


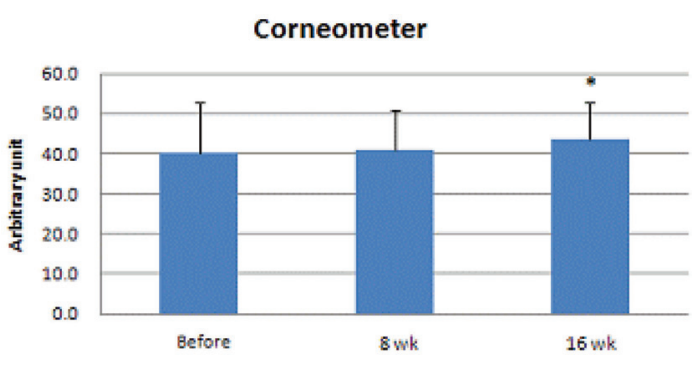

Fig. 4. Results of skin surface moisture measurement showed an increase. At the 8th week, no significant increase was observed; however, it was significantly higher at the 16 th week $\left({ }^{*} p<0.05\right)$.

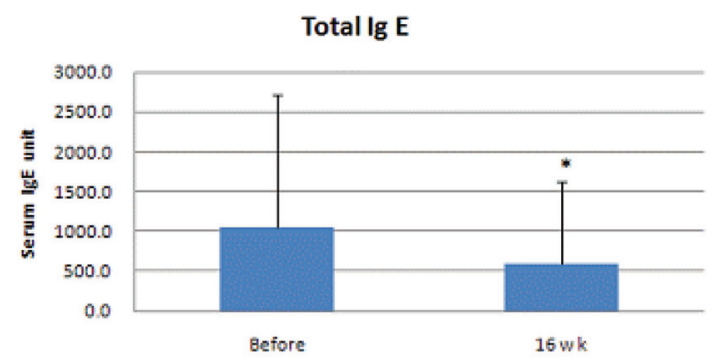

Fig. 5. Results of serum IgE level measurement. At the 8th week, no significant decrease was observed; however, at the 16th week, mean value was 588.9 , which demonstrated significant diminution of serum $\lg E\left({ }^{*} p<0.05\right)$

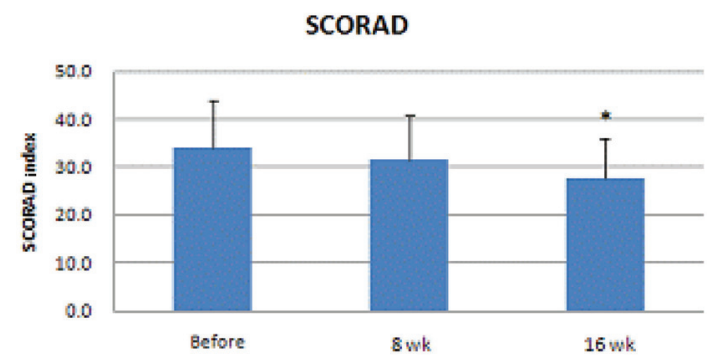

Fig. 6. Results of severity scoring of the atopic dermatitis (SCORAD) index measurement showed a continuous decrease after the 8th and 16 th weeks, and diminution of the 16 th week was statistically significant $\left({ }^{*} p<0.05\right)$.

\section{Measurement of severity by the SCORAD index}

SCORAD index ranged from 18 to 58, indicating that enrolled patients were included in the moderate to severe AD group. SCORAD index showed a continuous decrease after the 8th and 16th weeks and the diminution at the 16th week was statistically significant $(p<0.05)$ (Fig. 6).

\section{Safety assessment}

In this study, no specific side effect, such as gastrointestinal trouble, skin rashes, etc. was observed in the KRG medicated patient group.

\section{DISCUSSION}

$\mathrm{AD}$ is a chronic recurrent pruritic eczematous condition that usually occurs during infancy [17-20]. It often emerges as an initial signal of atopic march, which progresses to allergic rhinitis and asthma in older age [21]. In general, the prevalence and severity of $\mathrm{AD}$ decreases with age. However, a recent study comparing prevalence and severity of the last decade with nowadays reported a significant increase of both [22-24].

Many researchers believe that KRG has potential for use as a new therapeutic modality for treatment of dermatologic disease. Our previous study showed that KRG may be helpful in treatment of androgenic alopecia [25]. However, there are certain limitations of correlation between AD and KRG. Bae et al. [6] and Shin et al. [7] reported on improvement of $\mathrm{AD}$ and contact dermatitis by KRG through cytokine regulation in mouse animal models. However, clinical research on the efficacy of $\mathrm{KRG}$ in treatment of $\mathrm{AD}$ has not yet been reported.

Ginsenosides are the major components of KRG [26], and the anti-allergic and anti-inflammatory effects of ginsenoside $\mathrm{Rh}_{1}$, anti-allergic effect of ginsenoside $\mathrm{Rh}_{2}$, and antiallergic and anti-contact dermatitis activity of $\mathrm{KRG}$ and ginsenosides $\mathrm{Rg}_{3}, \mathrm{Rf}$, and $\mathrm{Rh}_{2}$ have already been identified [27-29]. The anti-allergic properties of KRG and ginsenosides have strongly suggested their possibility as potential anti-atopic agents [30]. Recently, the effect of topical KRG and ginsenosides in AD has been reported in TNCB-induced AD-like skin lesions in NC/Ngamice. Results showed that application of topical KRG resulted in suppression of mast cell number, TNF- $\alpha$ mRNA, and IL-4 mRNA level, which might lead to a significant decrease of TNCB-induced ear thickening [30]. Although this study was both an animal model test and a topical agent application test, unlike our study, the significant decrease of mRNA expression level of TNF- $\alpha$, IL- 4 , and mast cell numbers might be correlated with the mechanism of how KRG induces improvement of $\mathrm{AD}$.

In this study, the authors were able to verify the clinical efficacy of KRG using the SCORAD index of skin and TEWL, DI, SI, and skin surface moisture rate using medical engineering methods. In particular, at the 16th week after initiation, all of the indexes and results showed statistically significant improvement. And serum $\operatorname{IgE}$ level also showed a significant decrease, which shows accordance with Kobayashi et al. [31], who reported that 'Hochu-ekki-to', an herbal medicine including ginseng, induced a significantly improved response 
in the treatment resistant $\mathrm{AD}$ patient group, with a significant decrease of serum IgE.

These results suggest that treatment with KRG can result in improved skin barrier function and lower serum IgE. However, as this is a clinical study, the authors think that further basic studies of the mechanism of KRG in $\mathrm{AD}$ may be required. In conclusion, the authors demonstrated that KRG may be a helpful functional food for use in management of $\mathrm{AD}$.

\section{ACKNOWLEDGEMENTS}

This study was supported by the 2009 grant from the Korean Society of Ginseng funded by Korea Ginseng Corporation.

\section{REFERENCES}

1. Addor FA, Aoki V. Skin barrier in atopic dermatitis. An Bras Dermatol 2010;85:184-194.

2. Vickery BP. Skin barrier function in atopic dermatitis. Curr Opin Pediatr 2007;19:89-93.

3. Kawashima M. Skin barrier dysfunction in atopic dermatitis. Nippon Rinsho 2005;63 Suppl 5:86-90.

4. Simpson EL. Atopic dermatitis: a review of topical treatment options. Curr Med Res Opin 2010;26:633-640.

5. Nakamura K. Treatment of atopic dermatitis. Arerugi 2009;58:1386-1393.

6. Bae EA, Han MJ, Shin YW, Kim DH. Inhibitory effects of Korean red ginseng and its genuine constituents ginsenosides $\mathrm{Rg}_{3}, \mathrm{Rf}$, and $\mathrm{Rh}_{2}$ in mouse passive cutaneous anaphylaxis reaction and contact dermatitis models. Biol Pharm Bull 2006;29:1862-1867.

7. Shin YW, Bae EA, Kim SS, Lee YC, Lee BY, Kim DH. The effects of ginsenoside Re and its metabolite, ginsenoside $\mathrm{Rh}_{1}$, on 12-O-tetradecanoylphorbol 13-acetate- and oxazolone-induced mouse dermatitis models. Planta Med 2006;72:376-378.

8. Son SW, Park SY, Ha SH, Park GM, Kim MG, Moon JS, Yoo DS, Oh CH. Objective evaluation for severity of atopic dermatitis by morphologic study of skin surface contours. Skin Res Technol 2005;11:272-280.

9. Hendrix SW, Miller KH, Youket TE, Adam R, O'Connor RJ, Morel JG, Tepper BE. Optimization of the skin multiple analyte profile bioanalytical method for determination of skin biomarkers from D-Squame tape samples. Skin Res Technol 2007;13:330-342.

10. Serup J, Winther A, Blichmann C. A simple method for the study of scale pattern and effects of a moisturizer: qualitative and quantitative evaluation by D-Squame tape compared with parameters of epidermal hydration. Clin Exp Dermatol 1989;14:277-282.

11. Pinnagoda J, Tupker RA, Agner T, Serup J. Guidelines for transepidermal water loss (TEWL) measurement. A report from the Standardization Group of the European Society of Contact Dermatitis. Contact Dermatitis 1990;22:164178.

12. Alanen E, Nuutinen J, Nicklen K, Lahtinen T, Monkkonen $\mathrm{J}$. Measurement of hydration in the stratum corneum with the MoistureMeter and comparison with the Corneometer. Skin Res Technol 2004;10:32-37.

13. Hashimoto-Kumasaka K, Takahashi K, Tagami H. Electrical measurement of the water content of the stratum corneum in vivo and in vitro under various conditions: comparison between skin surface hygrometer and corneometer in evaluation of the skin surface hydration state. Acta Derm Venereol 1993;73:335-339.

14. Werner Y. The water content of the stratum corneum in patients with atopic dermatitis. Measurement with the Corneometer CM 420. Acta Derm Venereol 1986;66:281284.

15. Finlay AY. Measurement of disease activity and outcome in atopic dermatitis. Br J Dermatol 1996;135:509-515.

16. Kunz B, Oranje AP, Labreze L, Stalder JF, Ring J, Taieb A. Clinical validation and guidelines for the SCORAD index: consensus report of the European Task Force on Atopic Dermatitis. Dermatology 1997;195:10-19.

17. Sharma L. Diagnostic clinical features of atopic dermatitis. Indian J Dermatol Venereol Leprol 2001;67:25-27.

18. Yamada H. Natural history of atopic dermatitis-outsideinside-outside story. Nihon Rinsho Meneki Gakkai Kaishi 2010;33:118-125.

19. Taieb A. The natural history of atopic dermatitis. J Am Acad Dermatol 2001;45(1 Suppl):S4-S5.

20. Novembre E, Cianferoni A, Lombardi E, Bernardini R, Pucci N, Vierucci A. Natural history of "intrinsic" atopic dermatitis. Allergy 2001;56:452-453.

21. Luoma R, Koivikko A, Viander M. Development of asthma, allergic rhinitis and atopic dermatitis by the age of five years. A prospective study of 543 newborns. Allergy 1983;38:339-346.

22. Montealegre F, Meyer B, Chardon D, Vargas W, Zavala D, Hart B, Bayona M. Comparative prevalence of sensitization to common animal, plant and mould allergens in subjects with asthma, or atopic dermatitis and/or allergic rhinitis living in a tropical environment. Clin Exp Allergy 2004;34:51-58.

23. Sanz Ortega J, de la Cuadra Oyanguren J, Martorell Aragones A, Torro Domenech I, Cerda Mir J, Alvarez Angel V. Prevalence of sensitivity to contact allergens among 
atopic and non atopic children without dermatitis. An Esp Pediatr 1990;33:339-342.

24. Jarvis D, Burney P. ABC of allergies. The epidemiology of allergic disease. BMJ 1998;316:607-610.

25. Kim JH, Yi SM, Choi JE, Son SW. Study of the efficacy of Korean red ginseng in the treatment of androgenic alopecia. J Ginseng Res 2009;33:223-228.

26. Wu JY, Gardner BH, Murphy CI, Seals JR, Kensil CR, Recchia J, Beltz GA, Newman GW, Newman MJ. Saponin adjuvant enhancement of antigen-specific immune responses to an experimental HIV-1 vaccine. J Immunol 1992;148:1519-1525.

27. Park EK, Choo MK, Han MJ, Kim DH. Ginsenoside Rh possesses antiallergic and anti-inflammatory activities. Int Arch Allergy Immunol 2004;133:113-120.

28. Bae EA, Han MJ, Shin YW, Kim DH. Inhibitory effects of Korean red ginseng and its genuine constituents gin- senosides $\mathrm{Rg}_{3}$, Rf, and $\mathrm{Rh}_{2}$ in mouse passive cutaneous anaphylaxis reaction and contact dermatitis models. Biol Pharm Bull 2006;29:1862-1867.

29. Park EK, Choo MK, Kim EJ, Han MJ, Kim DH. Antiallergic activity of ginsenoside $\mathrm{Rh}_{2}$. Biol Pharm Bull 2003;26:1581-1584.

30. Kim HS, Kim DH, Kim BK, Yoon SK, Kim MH, Lee JY, Kim HO, Park YM. Effects of topically applied Korean red ginseng and its genuine constituents on atopic dermatitis-like skin lesions in NC/Nga mice. Int Immunopharmacol 2011;11:280-285.

31. Kobayashi H, Mizuno N, Teramae H, Kutsuna H, Ueoku S, Onoyama J, Yamanaka K, Fujita N, Ishii M. Diet and Japanese herbal medicine for recalcitrant atopic dermatitis: efficacy and safety. Drugs Exp Clin Res 2004;30:197202. 